\title{
Catulo, c. 59. El castigo de Rufa
}

\author{
Catullus, c. 59. The Punishment of Rufa
}

\author{
Emilio ZAINA \\ Universidad Nacional del Sur, Argentina \\ ezaina@criba.edu.ar
}

\begin{abstract}
Resumen: El poema 59 de Catulo ha recibido escasa atención de la crítica especializada, probablemente por su apariencia fragmentaria y su obscenidad irremisible. También por el lugar que ocupa en la colección ${ }^{1}$ y por estar dirigido a una mujer de ínfima condición que aparece sólo una vez en todo el corpus. Sin embargo, los versos del c. 59 pertenecen con todo derecho al universo catuliano por su contenido ${ }^{2}$ y también por su técnica compositiva.
\end{abstract}

ABSTRACT: Catullus' poem 59 has received minor attention from specialized critics, probably due to its fragmentary nature and wide obscenity. It is also so, because of the place that the poem occupies in the collection, as well as being addressed to an ill-reputed woman who only appears once in the whole corpus. Nonetheless, the verses from this poem belong completely to the $\mathrm{Ca}-$ tullian universe, given its content and compositional technique.

Palabras Clave: Catulo; c. 59; colección; obscenidad; técnica compositiva.

KeYwords: Catullus; c. 59; Collection; Obscenity; Compositional Technique.

RECIBIDO: 14 de septiembre de 2014 - ACEPTADO: 1 de febrero de 2016.

DOI: 10.19130/iifl.nt.2016.33.2.710

Bononiensis Rufa Rufulum fellat, uxor Meneni, saepe quam in sepulcretis vidistis ipso rapere de rogo cenam,

1 Skinner 1980a, p. 74: "a jumble of unrelated and curiously unfinishe verses". Hubbard 1983, p. 220: "C. 52-60, which, while not without moments of inspiration, on the whole form a rather embarrassing grab-bag of doggerel and fragments at the end of the polimetry section”. Más acertada es la opinion de Quinn 1970, p. 262: “An elegantly structured epigram, rather than a lampoon".

${ }^{2} \mathrm{Si}$ atendemos a algunos de sus aspectos temáticos más obvios, constatamos que el motivo del hambre reaparece en cc. $21 ; 23$ y c. 23 (que se refiere a la pobreza de Aurelio y su familia e, indirectamente, al hambre que soportan) y cc. 28.5 y 47.2. Podría añadirse la voracidad sexual y monetaria, según Richlin 1988, pp. 355-363. La práctica de la fellatio se reitera en cc. $10.12 ; 16.1,14 ; 21.8,13 ; 28.10 ; 37.8 ; 74.5$ y 80 passim. Cito sólo aquellos poemas en que aparecen los verbos irrumare y fellare. Añado c. 80 en el que no se citan dichos verbos, pero es obvia la actividad sexual que se lleva a cabo. El robo aparece en los cc. 12, 25, 29, 33, 42, entre otros poemas. 
cum devolutum ex igne prosequens panem ab semiraso tunderetur ustore. ${ }^{3}$

El poema presenta dos escenas sucesivas. La primera de ellas alude a las prácticas sexuales de Rufa y la siguiente describe el latrocinio de esa misma mujer y el castigo que el ustor le propina. De la segunda escena han sido testigos frecuentes los destinatarios explícitos de la pieza (saepe ... vidistis); la otra escena, que en la sucesión de los versos es la primera, introduce información novedosa para esos mismos destinatarios explícitos. ${ }^{4}$ El cuadro que el poema expone podría calificarse como fulgurante: una pira funeraria encendida, dos seres pelirrojos y otro con la cabeza rapada a medias.

\section{Testas coronadas}

Rufa era un cognomen usual en la Galia Cisalpina y también un epíteto referido a la coloración de la cabellera. ${ }^{5}$ Por supuesto, las dos posibilidades coexisten sin conflicto, si admitimos que los cognomina latinos aludían muchas veces a alguna característica distintiva de quien lo portaba. Por otra parte, el término rufa podía contener una carga semántica negativa, muy adecuada a la oprobiosa conducta de una mujer que fre-

${ }^{3}$ Utilizo la edición de Goold, 1983.

${ }^{4}$ Me refiero a los destinatarios en los poemas de Catulo, Zaina 2010, pp. 1-23.

${ }^{5}$ En la colección de Catulo la referencia al cabello es recurrente, al punto que puede esbozarse un principio de clasificación. El rubio cabello de los héroes (flavus): Teseo, c. 64.98 y Protesilao, c. 68.130. El cabello también rubio, flavua, de las mujeres mitológicas: Ariadna, c. 64.63 y Berenice, c. 66.62 (podrían agregarse otras mujeres terrenales, si bien el adjetivo utilizado es candida, referido con más seguridad a la coloración de la piel, aunque el cabello no queda exento: la amiga que podría traer Fabulo en c. 13.4; la enamorada de Cecilio en c. 35.8; Lesbia, c. 68.70, Quintia, c. 86.1); la costumbre de llevar largos cabellos por parte de los provincianos: la Gallia comata en 29.3 y el hispano Ignacio, capillatus en c. 37.17. Los ancianos, naturalmente canos: Egeo, c. 64.224; las ancianas que pierden a sus hijos en la guerra en c. 64.350; Tetis, en c. 66.70; un viejo en c. 68.124 y Cominio, en c. 108.1. El vello crecido de los exoleti: tal vez Furio y Aurelio, pero no queda claro en c. 16.10 y Vibenio en c. 33.7. La ausencia de vello, glaber, de los pueri que el amo, pronto a contraer nupcias, debe abandonar en c. 61.135. Sobre la diferencia entre capillus y pilus y capillatus y pilosus, se puede consultar en André 1991, pp. 212-213. 
cuentaba las tumbas. ${ }^{6}$ Con Rufulus la cuestión es parecida. Algunos especialistas pretenden que se designaba así a una clase de tribuno militar, ${ }^{7}$ pero es mucho más natural considerarlo un diminutivo y una derivación de Rufa para describir a alguien también pelirrojo. ${ }^{8}$

Por otra parte, el ustor, que en el poema se ocupa de los cuerpos de los difuntos, tiene la cabeza semirrapada, tal como la portaban los esclavos que habían cometido algún crimen. Rasurar la cabeza, marcar el cuerpo con signos o atenazarlo con collares escritos constituían diferentes medios de escarmiento y también de identificación de los esclavos criminales. ${ }^{9}$ El poeta toma una parte del cuerpo y la pone de relieve, una técnica descriptiva usual en su colección ${ }^{10}$ que aquí se actualiza con el cabello de las testas de Rufa, Rufulus y el ustor. No hay ninguna sorpresa en las têtes couronées de c. 59 para un lector avezado que recuerde la nariz de Fabulo (c. 13), los dientes de Emilio (c. 97.5) o el pie de Lesbia (c. 68.70-71). Los teóricos de la literatura han señalado que éste es un dispositivo utilizado para lograr el effet de réel. ${ }^{11}$ En muy pocas ocasio-

${ }^{6}$ Munro 1878, p. 134, observa que "rufus was a common term of reproach" y cita los siguientes pasajes en apoyo de su afirmación: Plaut., Asin., 2. 3.20; Tert., Heaut., 5. 5.17, y Mart., 2. 32 y 12.32.4.

${ }^{7}$ Cf. Ellis 1889, p. 205, retomado por Thomson 1998, p. 345.

${ }^{8}$ La paronimia es frecuente en Catulo: Veranius... Veraniolus c. 12.16-17; Cato, Catullum c. 56.3; Aufillenum ... Aufillenam c. 100.1.

${ }^{9}$ El hecho de que fuera semirasus permite suponer que era un esclavo fugitivo, cf. Apul., Met., 9.12: "frontem litterati et capillum semirasi et pedes anulati". En Marcial 8.75.9, inscripti alude a los esclavos públicos que estaban encargados de transportar cadáveres. Extensa información puede hallarse en Jones 1987, pp. 139-155, y Gustafson 1997, pp. 79-105. Sobre los collaria servorum fugitivorum, cf. Dessau 1906, inscripciones 8726-8733. Un pasaje lleno de interés se encuentra en la lex locationis de munere publico libitinario $(A E, 1971,0088)$ en el que se excluye a los esclavos marcados (neve stigmat(ibus) inscript(us) de las tareas funerarias. Por el contrario, Marcial, 8.25.9, describe el modo en que unos libitinarii tatuados transportaban un cadáver vil: "quattuor inscripti portabant vile cadaver". Catulo está más cerca de Marcial cuando amenaza a Talo con escribir sobre su cuerpo con latigazos quemantes en c. 25.11: "tibi conscribilent flagella". Sin duda, el castigo consistía en denunciar el latrocinio de Talo por medio de signos taraceados sobre su carne.

${ }^{10}$ Cf. Zaina 1995, pp. 19-25.

11 “C'est la prédominance de la métonymie qui gouverne et définit effectivement le courant littéraire qu'on apelle 'réaliste'... Suivant la voie des relations de contigüité, l'auteur réaliste opère des digressions métonymiques... Il est friand de détails synecdochiques" explica Jakobson 1966, pp. 62-63. 
nes Catulo se refiere a la entera superficie del cuerpo y a su contorno general. Prefiere, en cambio, tomar una de sus partes y colocarla en el centro de la escena, para exponerla a los ojos del lector. El effet de réel es un procedimiento próximo a la evidentia, ${ }^{12}$ un recurso retórico que tenía como propósito hacer surgir ante los ojos del receptor las imágenes descritas. Las cabezas rojizas de Rufa y de Rufulus y la cabeza semirrapada del ustor $^{13}$ sobresalen visibles en virtud de un dispositivo descriptivo que inclusive es reforzado por medio del uso del verbo vidistis, en v. 3. De este modo, los lectores alejados en el tiempo y en el espacio verán levantarse ante oculos la escena en la que tres seres de têtes couronées trajinan entre las tumbas de un cementerio antiguo.

\section{El poema y las inscripciones sepulcrales}

Vulpius consideró que era posible vincular el poema con un pasquín desplegado intra muros. ${ }^{14}$ Sin embargo, parece mucho más adecuado considerar que Catulo aprovechó la estructura de los epitafios para concretar el escarnecimiento público de una mujer que frecuentaba las tumbas. Los poetas latinos vivían inmersos en un paisaje epigráfico sobre el que influían y por el que eran influidos. ${ }^{15}$ La detallada identificación de Rufa es un dato sorprendente que debió haber despertado sospechas entre los lectores. ${ }^{16}$ De hecho, los loci similes citados por la crítica especializada, constituidos por repetitivas y escuetas inscripciones parietales,

${ }^{12}$ Sobre evidentia o enargeia, cf. el artículo de Zanker 1981, pp. 297-311.

${ }^{13}$ Ustor, el encargado de atizar el fuego - ignis, v. 4- de la pira funeraria, se vincula por su etimología con el verbo uro, "quemar". Usta era un pigmento rojo que se utilizaba para teñir, cf. Vitr., 7.11.2, y Plin., $H N, 35.38$.

14 Vulpius 1710, p. 187: "Libelli in principes viros contumeliosi, editi ab hominibus audacibus, et iracundia elatis, Romae hoc tempore vocantur pasquinate".

${ }^{15}$ En un brevísimo artículo, Horsfall 1986, pp. 44-45, ofrece una perspectiva diferente sobre el vínculo entre los poetas latinos y la epigrafía. Desde su punto de vista, los poetas canónicos vivían en un paisaje epigráfico que influía sobre ellos, por consiguiente también hay que buscar en los poetas del canon el influjo de la epigrafía sepulcral. El vínculo entre los CLE y Catulo ha sido estudiado especialmente por Popova 1970, pp. 312-366; Gómez Pallarès 1992, pp. 201-230, y Cugusi 1996, pp. 345-348.

${ }^{16}$ Varios especialistas señalan la detallada identificación de Rufa, pero no la relacionan con las inscripciones sepulcrales. Por ejemplo, Thomson, op. cit., p. 345, y Fernández Corte y González Iglesias 2006, p. 600. 
se parecen sólo en parte al c. 59:17 Saluia felat Antiocum CIL IV 1427; Sabina fellas non bene facis CIL IV 1485; Fortunata fellat CIL IV 2275; Ionas cum Fileto hic fellat CIL IV 2402; Rufa ita uale, quare bene felas CIL IV 2421. A diferencia de los lacónicos mensajes de las paredes, que contienen nombres sin mayor especificación, verbos y poco más, Catulo se demora en indicarnos el gentilicio y el cognomen Rufa, además del nombre de su cónyuge. Estas señas de identidad son datos inusitados en una inscripción parietal, pero constituyen noticias naturales en un epitafio. ${ }^{18}$ La explosión epigráfica, que se dio entre los siglos I a. C. y III de nuestra era, ${ }^{19}$ tuvo como fin principal salvar al nombre del olvido en una sociedad mayoritariamente escéptica respecto de la vida de ultratumba. ${ }^{20}$ Catulo parece utilizar los recursos típicos de los epitafios durante la casi totalidad del verso que abre el c. 59 con el mismo objetivo que tenían las inscripciones sepulcrales de su época: conservar en la memoria de los vivos los nombres, aunque en este caso con el propósito de hacer visible y mantener viva la identidad de una mujer acusada de cometer atrocidades entre las tumbas. Los cementerios, ubicados en las embocaduras de las ciudades antiguas, eran un lugar concurridísimo ${ }^{21}$ y las lápidas

${ }^{17}$ Citados, entre otros, por Baherens 1885 , p. 289; Kroll $1968^{5}$, p. 105 , y retomados por Quinn 1970, p. 262.

${ }^{18}$ Palmer 1891, pp. 7-8, propuso leer Rufuli en lugar de Rufulum: "Rufulum or rufulum is generally read for rufum, and Bononiensis is taken as nominative. It is in my judgment certainly accusative (cf. 58, 5). We should therefore read rufuli, which is nearer rufum than rufulum is. $\mathrm{L}$ is often undistinguishable from $\mathrm{i}$, and from one of the strokes of an, $\mathrm{m}, \mathrm{n}$, or u". Los editores actuales de Catulo no consideran la conjetura de Palmer. Sin embargo, es lícita desde el punto de vista paleográfico y podría coadyuvar a sostener nuestra postura. Si añadiéramos la filiación -Rufa Rufuli- al gentilicio, el cognomen y la mención del cónyuge, tendríamos la identificación más completa de cualquiera de los personajes de Catulo. Si aceptáramos la lectio de Palmer, deberíamos mantener Bononiensis como nominativo y, en consecuencia, desestimar la posibilidad del incesto que percibe buena parte de los estudiosos del poema.

${ }^{19}$ Además del clásico estudio de MacMullen 1982, pp. 233-246, cf. Meyer 1990, pp. 74-96, y Woolf 1996, pp. 22-39.

${ }^{20}$ Pikhaus 1987 , pp. 159-188, ofrece pruebas y porcentajes del extendido escepticismo respecto de la vida en ultratumba que se constata en la epigrafía sepulcral.

${ }^{21}$ A esto alude saepe ... vidistis en vv. 3-4 y no a un mecanismo que convierte a los lectores del poema en blanco de insultos como supone Nappa 1999, pp. 329-335, que cree ver en el poema el mismo dispositivo que en CIL IV 2360 y 4008. Aquello que Svenbro denomina "el paradigma pederástico de la escritura" no se constata en c. 59 sino, por ejemplo, en c. 37 donde el amante amenaza a los contubernales de la salax taberna con 
colocadas a la vera del camino tenían en su superficie une écriture en quête de lecteurs, ${ }^{22}$ apropiada para exponer a la vista de todos los paseantes no sólo las virtudes de los difuntos, sino también las inconductas humanas. ${ }^{23}$ En una época en la que el estado no tenía en sus manos la administración completa de la justicia, la denuncia pública era una forma usual de venganza y los cementerios un sitio privilegiado para llevarla a cabo. Acusaciones de crímenes, latrocinios o expresiones de encono eran frecuentes en las inscripciones sepulcrales antiguas, circunstancia que Catulo utilizó para trazar su invectiva en contra de Rufa.

¿Cómo conciliar la presencia del escazonte con la apertura "funeraria" del c. 59? La historia del coliambo está ligada a Hiponacte, un poeta satírico del s. VI a. C. y su uso en la epigrafía sepulcral latina, aunque atestiguado, es escaso. ${ }^{24}$ Es de mucho interés señalar que, antes de reconocer el verso como un escazonte, los lectores leemos las diez primeras sílabas como si se tratara de un trímetro yámbico y sólo cuando arribamos a las dos sílabas finales, coincidentemente con la aparición del brutal insulto implicado en el verbo fellat, advertimos que estamos ante un coliambo. Al menos esto es lo que percibía Marius Victorinus para quien alcanzaba con cambiar una sílaba para convertir un trímetro en un escazonte: "Fiat mutatu acenttu pro sedet sedit, erit claudus". ${ }^{25}$ Es sabido que la forma métrica sepulcral que alcanzó mayor difusión hacia el final de la República fue el senario yámbico, un verso popular derivado de la comedia, que permitía una cantidad de sustituciones en las cantidades inaceptables para el poeta neotérico. ${ }^{26}$ En cambio, el trímetro

someterlos por medio de la escritura. Cf. Svenbro 1993, pp. 187-204, y Zaina 2009, pp. 59-67.

22 De gran interés son los artículos de Corbier 1987, pp. 27-60 y 1991, pp. 114-116. El epitafio de Trimalción es un ejemplo famoso de los dispositivos para atraer la atención de los lectores caminantes. Aquellos transeúntes que desearan conocer la hora, necesariamente debían leer su inscripción sepulcral.

${ }^{23}$ Cf. Kajanto 1968, pp. 185-186.

${ }^{24}$ Sobre el uso del escazonte en las inscripciones sepulcrales latinas, cf. Galletier 1922, pp. 281-282.

${ }^{25}$ Marius Victorinus 174 G. 2575 P. Cf. también Atilius Fortunatus 2673 P. 314 G.: "ac pro sedet, sedit erit scazon". Ambos gramáticos toman como ejemplo el segundo verso del c. 52 de Catulo, un pequeño poema que, justamente, combina el tema de la muerte con la invectiva.

${ }^{26}$ Catulo utiliza el trímetro yámbico puro en cc. 4 y 29, y el trímetro yámbico que admite sustituciones en las sílabas iniciales del primero y tercer pie en c. 52. El metro se- 
"a la griega" fue utilizado, si bien de manera restringida, por un público romano sumamente cultivado para trazar versos sobre las tumbas. ${ }^{27}$ Los lectores del c. 59 leemos las diez primeras sílabas del verso de apertura como si se tratara de un trímetro yámbico, un metro adecuado, en manos del poeta neotérico, para una inscripción sepulcral. ${ }^{28}$

El epitafio de Arquímedes, que Cicerón conservaba en la memoria, también estaba trazado en este metro:

... cuius ego quaestor ignoratum ab Syracusanis, cum esse omnino negarent, saeptum undique et vestitum vepribus et dumetis indagavi sepulcrum. tenebam enim quosdam senariolos, quos in eius monumento esse inscriptos acceperam, qui declarabant in summo sepulcro sphaeram esse positam cum cylindro. ${ }^{29}$

El pasaje de Cicerón proporciona una preciosa información sobre el uso del trímetro yámbico en la epigrafía sepulcral griega ${ }^{30}$ y sobre el conocimiento que los latinos tenían de esta práctica. Sin duda, los senariolos que el orador recordaba eran un dato cultural compartido por sus contemporáneos para quienes un epitafio bien podía estar construido con este metro.

pulcral más utilizado durante la época de Catulo fue el senario yámbico, nunca usado por el poeta neotérico seguramente a causa de las excesivas libertades y licencias prosódicas que esta forma popular, derivada de la comedia, permitía. Sobre el uso del senario en las inscripciones sepulcrales durante el periodo de la República, cf. el extenso y pormenorizado estudio de Massaro 1992, especialmente pp. 8-25.

${ }^{27}$ Cf. Galletier, op. cit., p. 297.

${ }^{28}$ En c. 59, la línea se revela como un coliambo hacia el final del verso, en tanto que la primera parte se comporta como un trímetro yámbico. Cada sección aludiría a diferentes esferas, la primera (Bononiensis Rufa Rufulum/i) funeraria, la segunda (fellat) satírica. La apertura del poema bien podría ser la de una inscripción sepulcral, en tanto que el verbo que clausura la línea, típico de una inscripción parietal, permanece encerrado, también por el comienzo del segundo verso (uxor Meneni), por las señas de identidad de Rufa. El mismo recurso es utilizado por Catulo en c. 95.1 que comienza como un hexámetro heroico (Annales Volusi) y finaliza con burlones yambos (cacata charta), cf. Morgan 2010, pp. 88-92.

${ }^{29}$ Tusc., 5.64 .

${ }^{30}$ Sobre el uso del trímetro yámbico en la epigrafía funeraria griega, cf. Kantzios 2005, p. 142. 


\section{El poeta airado}

Catulo utiliza las posibilidades que ofrece la escritura expuesta de los sepulcros para castigar la conducta de Rufa. En el marco de la tradición del poeta airado, elaborada por Arquíloco e Hiponacte, el poeta revela los crímenes del adulterio, la fellatio y el hambre desmesurada de una mujer que viola los tabúes del mundo de los muertos. El poema guarda un castigo interno para Rufa, un ajusticiamiento que, de nuevo, no proviene de la administración estatal. El incinerador semirrapado a causa de sus crímenes, y probablemente por este motivo condenado a un trabajo ímprobo en las márgenes de la ciudad, es el encargado de la punición a las faltas de Rufa. ${ }^{31} \mathrm{Si}$ Catulo sanciona por medio de la denuncia verbal, desde el lugar de superioridad que la tradición le concede al poeta airado, el ustor apalea, ${ }^{32}$ desde su condición de igual o semejante, y mantiene en su estado de hambrienta desesperada a Rufa. ${ }^{33}$ El delegado por Catulo para aplicarle a la mujer el castigo por sus crímenes es, él mismo, un castigado por crímenes previos, tal como lo advierten los signos de su cabeza. Rufa concentra sobre sí acusaciones gravísimas: es una bustirapa ${ }^{34}$ sospechosa de cometer adulterio, además de trajinar en el cementerio como una moecha bustuaria. Su ajusticiador es otro marginal, un esclavo que ejerce la horrible tarea de ustor, una tarea que era inherentemente "sucia". El incinerador de cadáveres ocupaba el punto más bajo de la escala de los que se dedicaban a los trabajos funerarios y, si bien colaboraba en limpiar la ciudad de la polución, él mismo era

${ }^{31}$ Baehrens, op. cit., p. 289, señala: “admodum graphice persequitur poeta furantis de rogo feminae imaginem: adstat illa anidos circumiciens oculos, uidet flammae late sparsae ui detrudi ex rogo panem (liba maxime inicere solebant: CIL. III, 2919), adsilit detrusum captatura, a seruo ignes rogi custodiente baculi ferrei ictu feritur abigiturque mulier contempta ab homine contempto". Lateiner 1977, p. 18, en la misma línea que Baehrens, define el castigo de Rufa como "a tiny universe of just retribution".

32 Syndikus 1984, p. 287, señala las aliteraciones Rufa/Rufulum, saepe/sepulcretis, rapere/rogo, prosequens/panem y no tunderetur/ ustore que imita los golpes del ustor. Sobre las implicancias sexuales de tundo, cf. Adams 1982, p. 148, y Skinner 1980b, pp. 306-307, quienes citan pertundo de c. 32.11 y recuerdan a Pertunda, la deidad que presidía la pérdida de la virginidad.

${ }^{33}$ Baehrens, op. cit., p. 290, considera que los "ustores sumebantur ex seruis pessimis" y añade las referencias correspondientes: Cic., Pro Mil., 33, 90; Lucan., 8, 738, y Mart., 3, 93, 26.

${ }^{34}$ Cf. Plaut., Pseud., 361. 
alcanzado por la mácula que, como una infección, se propaga cuando se pone en contacto con Rufa, ${ }^{35}$ la otra impura de la escena. Como si no fuera bastante, los citadinos son convocados como terceros para desempeñar el papel de cómplices del escarmiento a Rufa y, al mismo tiempo, todos los futuros lectores del libellus entregado a Cornelio para que dure plus uno saeclo.

\section{BIBLIOGRAFÍA}

Adams, N., The Latin Sexual Vocabulary, Baltimore, The Johns Hopkins University Press, 1982.

ANDRÉ, J., Le Vocabulaire Latin de L'Anatomie, Paris, Les Belles Lettres, 1991.

Baherens, Ae., Catulli Veronensis Liber, Leipzig, Teubner, 1885.

Bodel, J., "Dealing with the dead: undertakers, executioners and potter's fields in ancient Rome", en V. M. Hope y E. Marshall (eds.), Death and Disease in the Ancient City, London, Routledge, 2000, pp. 128-151.

CORBIER, M., "L'écriture dans l'espace public romain", en L'Urbs: Espace urbaine et histoire ler siècle avant J.-IIIe siècle aprés J.-C.: Actes du colloque international organisé par le Centre national de la recherche scientifique et l'École française de Rome, Collection de l'École Française de Rome, Rome, École Française de Rome, 1987.

-, "L'écriture en quête de lecteurs", en Literacy in the Roman World, Ann Arbor, 1991.

Cugusi, P., Aspetti letterari dei carmina latina epigraphica, Bologna, Pàtron, 1996.

Dessau, H., Inscriptiones Latinae Selectae, Berlín, Weidmann, 1906.

Ellis, R., A Commentary on Catullus, Oxford, Clarendon Press, 1889.

Fernández Corte, C., y J. A. González Iglesias, Catulo. Poesías, Madrid, Cátedra, 2006.

GALlETIER, E., Étude sur la poésie funéraire romaine d'après les inscriptions, Paris, Hachette, 1922.

Gómez Pallarès, J., "Poetas latinos como escritores de Cle", $C F C$, 2, 1992, pp. 201-230.

${ }^{35}$ La práctica de la fellatio convierte a Rufa en impura: "oral sex was stigmatized as particularly reprehensible for the pollution it was thought to bring upon the performer" señala Richlin 1992, p. 27. Cf. también Williams 2010, pp. 218-224, en donde analiza el par purus/impurus en relación con el sexo oral. Por su parte, el ustor es también un personaje manchado. Los que manipulaban cadáveres contribuían a la higiene de las ciudades antiguas pero esa misma tarea los convertía en maculati. Entre quienes consideran la cuestión están: Bodel 2000, pp. 134-143, y Kyle 1998, pp. 155-160. 
Goold, G. P., Catullus, London, Duckworth, 1983.

Gustafson, M., "Inscripta in fronte: Penal Tattoing in Late Antiquity", CA, 16/1, 1997, pp. 79-105.

Horsfall, N., "Virgil and the inscriptions: a reverse view", $L C M, 11,1986$, pp. 4445.

Hubbard, T. K., “The Catullan Libellus”, Philol., 127, 1983, pp. 218-237.

JAKOBSOn, R., Essais de linguistique générale, Paris, Éditions de Minuit, 1966.

Jones, C. P., "Stigma: Tattooing and Branding in Graeco-Roman Antiquity", JRS, 77, 1987, pp. 139-155.

KAJANTO, I., "On the Freedom of Expression in Latin Epitaphs", Latomus, 27, 1968, pp. 185-186.

Kantzios, I., The Trajectory of Archaic Greek Trimeters, Leiden, Brill, 2005.

Kroll, W. C., Valerius Catullus. Herausgegeben und Erklä, Stuttgart, Teubner, $1968^{5}$.

KYLE, D. G., Spectacles of Death in Ancient Rome, London-New York, Routledge, 1998.

LATEINER, D., “Obscenity in Catullus”, Ramus, 6, 1977, pp. 15-32.

MacMullen, R., "The Epigraphic Habit in the Roman Empire”, AJP, 103/3, 1982, pp. 233-246.

MASSARo, M., Epigrafia metrica latina di età republicana, Bari, Università di Bari, 1992.

Meyer, E. A., "Explaining the epigraphic habit in the Roman Empire: the evidence of Epitaphs", JRS, 80, 1990, pp. 74-96.

Morgan, L., Musa Pedestris. Metre and Meaning in Roman Verse, Oxford, Oxford University Press, 2010.

Munro, H. A. J., Criticisms and elucidations of Catullus, Cambridge, Deighton, 1878.

NAPPA, Ch., "Catullus 59: Rufa Among the Graves", CP, 94/3, 1999, pp. 329-335.

Palmer, A., "Catulliana", CR, 5, 1891, pp. 7-8.

PikHaus, D., "La poésie épigraphique en Cispadane", en Cispadana e letteratura antica a cura del Dipartimento di Storia Antica dell' Università di Bologna, Bologna, Deputazione di Storia e Patria, 1987, pp. 159-188.

Popova, Z., "Influence de Catulle sur Carmina Latina Epigraphica”, Ann. Univ. Sofia Fac. Lettres, 63/2, 1970, pp. 312-366.

Quinn, K., Catullus: The Poems, London, MacMillan, 1970.

Richlin, A., "System of Food Imagery in Catullus", CW, 81, 1988, pp. 355-363.

- The Garden of Priapus. Sexuality and Aggression in Roman Humor, New York, Oxford University Press, 1992.

Skinner, M. B., Catullus'Passer: The Arrangement of the Book of Polimetric Poems, Salem, Ayer, 1980a.

—, "Pertundo tunicamque et palliumque", $C W, 73,1980$ b, pp. 306-307.

Svenbro, J., Phrasikleia. An Anthropology of Reading in Ancient Greece, IthacaLondon, Cornell University Press, 1993. 
Syndikus, H. P., Catull. Eine Interpretation, Darmstadt, Wissenschaftliche Buchgesellschaft, 1984.

Thomson, D. F. S., Catullus, Toronto, University of Toronto Press, 1998.

Vulpius, J. A., C. Valerius Catullus Veronensis et in eum novus commentarius, Patavii, Josephus Cominus, 1710.

Williams, C., Roman Homosexuality, New York, Oxford University Press, 2010.

Woolf, G., "Monumental writing and the expansion of Roman Society in the Early Empire", JRS, 86, 1996, pp. 22-39.

ZAINA, E., "La descripción del cuerpo de Lesbia", Faventia, 17/1, 1995, pp. $19-25$.

-, La materialidad de la escritura en los poemas de Catulo, Amsterdam, Hakkert, 2009.

_, "Catulo: cc. 1,5 y 16. El lector, los antilectores y el público”, Maia, 62/1, 2010, pp. 1-23.

ZANKer, G., "Enargeia in the Ancient Criticism of Poetry", RhM, 124, 1981, pp. 297-311. 
